\title{
Finger Printing and Quantitative Analysis of Cuscuta chinensis Flavonoid Contents from Different Hosts by RP-HPLC
}

\author{
Maryam Shekarchi', Babak Mokhtari Kondori', Homa Hajimehdipoor ${ }^{3}$, Leila Abdi', \\ Mohsen Naseri' ${ }^{5}$, Mojgan Pourfarzib', Gholamreza Amin ${ }^{2,4 *}$ \\ ${ }^{1}$ Food and Drug Control Laboratories and Food and Drug Laboratory Research Center, MOH and ME, Tehran, \\ Iran \\ ${ }^{2}$ Department of Pharmacognosy, Faculty of Pharmacy, Tehran University of Medical Sciences, Tehran, Iran \\ ${ }^{3}$ Traditional Medicine and Materia Medica Research Center and Department of Traditional Pharmacy, School of \\ Traditional Medicine, Shahid Beheshti University of Medical Sciences, Tehran, Iran \\ ${ }^{4}$ Department of Traditional Medicine, Faculty of Pharmacy, Tehran University of Medical Sciences, Tehran, Iran \\ ${ }^{5}$ Clinical Trial Research Center of Traditional Medicine, Shahed University, Tehran, Iran \\ Email: ${ }^{*}$ amin@tums.ac.ir
}

Received 16 March 2014; revised 16 April 2014; accepted 23 April 2014

Copyright ( 2014 by authors and Scientific Research Publishing Inc.

This work is licensed under the Creative Commons Attribution International License (CC BY).

http://creativecommons.org/licenses/by/4.0/

(c) (i) Open Access

\section{Abstract}

Background: Cuscuta spp. known as dodders, have been used as traditional medicines in eastern and southern Asian countries for many disorders such as gastrointestinal, respiratory, endocrine, skin and neurological diseases (Drug of mania). Flavonoids are the main biologically active constituents in Cuscuta genus especially in $C$. chinensis. Our aim in this study was to identify and discriminate between $C$. chinensis samples which were collected from different hosts, by using the pattern recognition aided fingerprint analysis and comparison of the content of four major flavonoids (hyperoside, rutin, isorhamnetin, kaempferol). Material and methods: Samples were collected from nine different plants in the same time and place, dried, grinded and extracted with methanol $(80 \%)$ by repeated maceration. Extractions were evaluated by high performance liquid chromatography analysis and fingerprinting. Results: Beside chromatographic fingerprint using similarity index, we compared the content of 4 major flavonoids (hyperoside, rutin, isorhamnetin, kaempferol) of $C$. chinensis samples on different hosts. Coclusion: The results showed that there were significant differences between the content of four major flavonoids of nine $C$. chinensis samples, but chromatographic fingerprint by similarity index of more than 0.88 , showed that the sample consistency was similar. So, it was suggested that combination of chromatographic fingerprint and the content determination of major flavonoids could be used to evaluate the quality control of C. chinensis from different hosts.

\footnotetext{
${ }^{*}$ Corresponding author.
} 


\section{Keywords}

\section{Cuscuta chinensis, Fingerprint, Flavonoids, Hosts, Similarity}

\section{Introduction}

Cuscuta (Dodder) is a genus of about 100 - 170 species of yellow, orange or red (rarely green) parasitic plants which is treated as the specific genus in the family Cuscutaceae. Cuscuta Semen, which is a crude drug prepared from the seeds of Cuscuta chinensis Lam., is commonly used as traditional herbal medicine as a liver or kidney tonic, improving sexual function, regulating the body's endocrine, immune system, anticancer, immunostimulatory, and antioxidant activities. The active constituents of the $C$. chinensis include flavonols, lignans, quinic acid, and polysaccharide. These compounds have been suggested to be responsible for the pharmacology activities observed from C. chinensis. Flavonoids are the main biologically active constituents in cuscutae semen. In addition, quercetin, kaempferol and hyperoside have been reported to exhibit various pharmacological activities, which to some extent might elucidate the mechanism of clinical effects of this commonly used Chinese medicine. Their contents can be an important index in quality evaluation of this crude drug. Many fakes were found in the crude drug samples, which seriously influenced the drug's quality [1]. Chemometrics coupled with the high-performance liquid chromatography (HPLC) fingerprint had become one of the most frequently applied approaches in assisting the recognition of the origin of plants [2]. Fingerprint analysis is considered as one of the most powerful approaches in quality control of traditional medicine. Many methods have been proposed to evaluate the similarity or difference of herbal medicines, and all of them can be viewed as forms of similarity analysis of the fingerprints, for example analyzing of commercial product of L-tryptophan from six different manufacturers by using HPLC fingerprinting method [3]-[8]. Conventional research focuses mainly on the determination of the most active components, while fingerprinting can offer characterization of a complex system with a degree of quantitative reliability, which is consistent with the theory that all the components, not just the few active compounds, in traditional medicine are held to be responsible for the beneficial effects. Furthermore, fingerprint analysis in the term of Chemotaxonomy, can be used for identifying and assessing the authenticity, stability, plant taxonomy, geographical origins, and harvest time of medicinal herbs [9]. Selection of several major peaks or a certain region of the fingerprints has been accepted as a routine approach. As a matter of fact, this approach was not sufficient due to the complexity of the secondary metabolites contained in the herbs. So it is necessary to evaluate the whole HPLC fingerprint profiles of the samples for species authentication. Chemical pattern recognition offered an objective and effective tool for the classification of herbal medicines based on their fingerprint profiles [10]. However, fingerprint analysis only shows the result of similarity calculated based on the relative value with the selected marker compound as reference standard, and does not display the absolute quantity. Obviously, quantitative determination of some marker components is necessary [11]. In this study, chromatographic fingerprint and contents of the markers were applied for quality control of $C$. chinensis samples. This plant grows on different hosts but, it is said in Traditional Iranian Medicine (TIM) that C. chinensis (koshoos) which was used as herbal medicine has been collected from Alhagi maurorum. (Khar shotor) [12]. So we can compare another samples with the sample which was collected from Alhagi maurorum as standard sample. The herbal medicine may consist of hundreds of phytochemicals, and their contents vary depending on climate, region of growing and seasons of harvest [11]. C. chinensis is a common dodder and it grows on different plants and very different climates. To date, no such paper has been reported for the differentiation of $C$. chinensis by fingerprinting. In this study our aim was to consider if growing on different hosts has the same contents of biochemical components specially flavonoids as their biologically active constituents in this species or not. Differences between biological constituents may lead various pharmacological effects.

\section{Materials and Method}

\subsection{Plant Material}

C. chinensis was collected from $70 \mathrm{Km}$. on Qazvin-Karaj superhighway and botanical garden of faculty of pharmacy in summer of 2010, from nine plants (hosts) including 1) Tanacetum balsamita; 2) Foeniculum vul- 
gare; 3) Carthamus oxyacantha; 4) Artemisia annua; 5) Datura innoxia; 6) Vinca minor; 7) Datura stramonium; 8) Kochia scoparia; 9) Alhagi maurorum respectively. Samples were authorized and kept in Faculty of pharmacy herbarium, Tehran university of Medical Sciences, by Professor Gholamreza Amin.

\subsection{Chemicals}

Hyperoside, rutin, isorhamnetin and kaempferol standard materials were purchased from ROTH (Karlsruhe, Germany). All solvents were obtained from Merck Co. (Darmstadt, Germany). Water used in all the experiments was deionized by Purelab UHQ Elga.

\subsection{Preparation of Samples}

Powdered samples (300 mesh, $0.5 \mathrm{~g}$ ) were suspended in $80 \%$ methanol $(25 \mathrm{ml})$ and extracted in an ultrasonic bath for $1 \mathrm{hr}$. The suspension was filtered and the remaining powder was extracted two more times using $25 \mathrm{~mL}$ $80 \%$ methanol. After filtration, the filtrates were transferred to a $100 \mathrm{ml}$ volumetric flask and diluted with $80 \%$ methanol to volume. The obtained solution was filtered through a membrane filter ( $0.45 \mu \mathrm{m}$ pore size) prior to injection [1].

\subsection{Preparation of Standard Solutions}

Stock solutions of hyperoside, rutin, isorhamnetin and kaempferol $(0.05,0.2,0.2$ and $0.01 \mathrm{mg} / \mathrm{ml})$ were prepared separately in methanol $80 \%$. Standard multi flavonol solutions were made by using different amount of stock solutions $(1-10,10-60,10-70$ and $0.3-1.6 \mu \mathrm{g} / \mathrm{ml}$ for hyperoside, rutin, isorhamnetin and kaempferol, respectively). Stock and working standard solutions were prepared daily.

\subsection{Instrumentation}

The HPLC experiment was performed using a Waters Alliance system equipped with a vacuum degasser, quaternary detector. The UV spectra were collected across the range of $200-900 \mathrm{~nm}$, extracting $360 \mathrm{~nm}$ for chromatograms. Empower software was utilized for instrument control, data collection and data processing. The column was an ACE $\mathrm{C}_{18}(4.6 \times 250 \mathrm{~mm}, 5 \mu \mathrm{m})$. The mobile phase was a linear gradient with ortho-phosphoric acid 0.25\% (A)-acetonitrile (B) for 37 min starting with A:B (95:5) for 2 min, (90:10) for 5 min, A:B (85:15) for 3 min, A:B (80:20) for 13 min, A:B (70:30) for 5 min and A:B (50:50) for 4 min with equilibrating for ten min. The flow rate was $1 \mathrm{~mL} /$ minute. The injection volume for all samples and standards solutions was $10 \mu \mathrm{L}$ [1].

\subsection{Statistical Analysis}

The statistical significance of differences of flavonoids contents were estimated by analysis of variance (ANOVA) followed by TUKEY test. Mean separations were determined by least significant difference (LSD) at $\mathrm{p} \leq 0.05 \%$. For fingerprint comparison of chromatograms, the similarities of entire chromatographic profiles were analyzed among tested samples. The RRT and RPA of each characteristic peak to reference peak were calculated in the chromatograms. The similarity value has been calculated based on the below equation [13]:

$$
\text { Similarity }=\frac{\sum_{i=1}^{n} X_{i} Y_{i}}{\sqrt{\sum_{i=1}^{n} X_{i}^{2}} \sqrt{\sum_{i=1}^{n} Y_{i=1}^{2}}}
$$

$X_{i}$ : (n $\left.\geq 10\right)$ peak area of peak $i$ of each sample, $Y_{i}$ : peak area of peak $i$.

\section{Results and Discussion}

\subsection{HPLC-UV Analysis of C. chinensis}

The established analytical method was used to determine the content of four flavonoids of nine samples. The constituents of $C$. chinensis samples were well separated under the established HPLC condition. Four main flavonoids including rutin, hyperoside, isorhamnetin and kaempferol were recognized by comparing the retention times and UV spectra with standards. The HPLC chromatogram of four reference standards was shown in Figure 1.

In order to obtain stable and repeatable chromatographic fingerprint of $C$. chinensis injections for quality con- 
trol, the method validation of HPLC fingerprint analysis was performed on the basis of the retention time and the peak area. Six real samples of each sample were analyzed on the same day (intra-day) and three on consecutive days (inter-day), and then the relative standard deviations were calculated. Each sample was injected to HPLC thrice. The method validation results were shown in Table 1.

\subsection{Sample Analysis}

The newly established analytical method was subsequently applied to simultaneous determination of 4 main flavonoids in 9 samlpes of $C$. chinensis which were collected from different hosts. All samples were analyzed using the optimized extraction and HPLC conditions. Each sample was analyzed in triplicate to determine the mean content $\left(\mathrm{mg}^{-1} \mathrm{~g}^{-1}\right)$. Table 2 shows that Routin and Isorhamnetin were the main compounds, followed by Hyperosid and Kaemperol as the lowest. Sample 7 has the highest content of Routin. Either the contents of Hyperoside and Isorhamnetin are higher in sample 1 and 8 respectively. The lowest content of all samples is Kaempferol which is higher in sample 3. Comparison of flavonoids content between samples showed that the amounts of Routin and Isorhamnetin between all samples were significantly different except between samples 3 and 6 for Routin and 1 and 5 for Isorhamnetin. The amount of Hyperoside between samples 1 and 3, 3 and 9, 4 and 8,5 and 7 were not significantly different together and for Kaempferol there was no significant difference

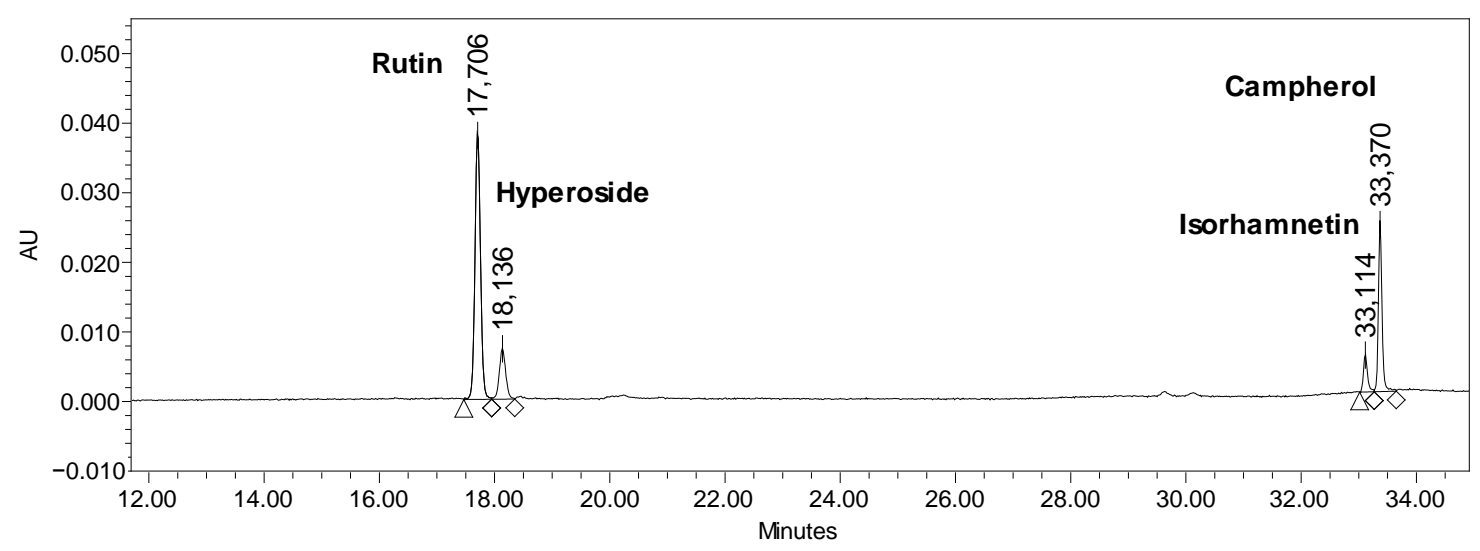

Figure 1. HPLC Chromatogram of rutin, hyperoside, isorhamnetin and kaempferol solution.

Table 1. HPLC method validation parameters of flavonoids contents in C. chinensis.

\begin{tabular}{cccccccc}
\hline Standards & LOD $^{*}$ & LOQ $^{*}$ & $\mathbf{R}^{\mathbf{2}}$ & RSD\% (Intra-day) & RSD\% (Inter-day) & Recovery \pm SD $^{\text {RT }^{* *}}$ \\
\hline Routin & 1.73 & 8.19 & 0.9990 & 1.3 & 3.4 & $90.3 \pm 6.0$ & 18.25 \\
Hyperoside & 0.09 & 4.19 & 0.9997 & 1.5 & 2.8 & $97.4 \pm 9.1$ & 18.76 \\
Isorhamnetin & 2.90 & 6.33 & 0.9994 & 1.3 & 3.3 & $98.7 \pm 7.9$ & 33.42 \\
Kaempferol & 0.18 & 0.56 & 0.9990 & 1.7 & 2.9 & $90.0 \pm 4.1$ & 33.67 \\
\hline
\end{tabular}

${ }^{*}$ Represents as $\mu \mathrm{g} / \mathrm{ml},{ }^{* *}$ Retention Time.

Table 2. Flavonoids content $\left(\mathrm{mg} \cdot \mathrm{g}^{-1}\right)$ of Cuscuta chinensis in different hosts.

\begin{tabular}{ccccccccccc} 
Host & $\begin{array}{c}\text { Tanacetum } \\
\text { balsamita }\end{array}$ & $\begin{array}{c}\text { Foeniculum } \\
\text { vulgar }\end{array}$ & $\begin{array}{c}\text { Carthamus } \\
\text { oxycantha }\end{array}$ & $\begin{array}{c}\text { Artemisia } \\
\text { annua }\end{array}$ & $\begin{array}{c}\text { Datura } \\
\text { innoxia }\end{array}$ & $\begin{array}{c}\text { Vinca } \\
\text { minor }\end{array}$ & $\begin{array}{c}\text { Datura } \\
\text { stramonium }\end{array}$ & $\begin{array}{c}\text { Kochia } \\
\text { scoparia }\end{array}$ & $\begin{array}{c}\text { Alhagi } \\
\text { marorum }\end{array}$ \\
\hline Routin & $6.10 \pm 0.41$ & $3.61 \pm 0.26$ & $6.97 \pm 0.53$ & $5.68 \pm 0.71$ & $7.35 \pm 0.67$ & $6.72 \pm 0.83$ & $9.42 \pm 0.1$ & $5.25 \pm 0.61$ & $8.48 \pm 0.19$ \\
Hyperoside & $1.25 \pm 0.11$ & $0.19 \pm 0.01$ & $1.23 \pm 0.12$ & $0.68 \pm 0.11$ & $0.48 \pm 0.07$ & $0.88 \pm 0.08$ & $0.52 \pm 0.04$ & $0.67 \pm 0.18$ & $1.18 \pm 0.08$ \\
Isorhamnetin & $5.67 \pm 0.48$ & $1.11 \pm 0.05$ & $14.38 \pm 0.25$ & $7.95 \pm 0.32$ & $5.56 \pm 0.16$ & $4.23 \pm 0.58$ & $5.03 \pm 0.34$ & $14.92 \pm 0.74$ & $6.64 \pm 0.23$ \\
Kaempferol & $0.07 \pm 0.01$ & $0.07 \pm 0.01$ & $0.11 \pm 0.01$ & $0.08 \pm 0.01$ & $0.08 \pm 0.01$ & $0.08 \pm 0.01$ & $0.08 \pm 0.01$ & $0.09 \pm 0.01$ & $0.09 \pm 0.01$ \\
\hline
\end{tabular}

${ }^{*}$ Results are mean \pm sd of three samples 
between samples 1, 4, 5, 6 and 7 all together. From these results it could be concluded that Routin and Isorhamnetin are the most important distinguishing markers for $C$. chinensis samples which were collected from different hosts.

\subsection{HPLC Fingerprints of $C$. chinensis Samples}

To standardize the fingerprint, nine samples were analyzed. Peaks that existed in all nine samples with reasonable heights and good resolution were assigned as "characteristic peaks" for identification of the plant. There were nine characteristic peaks in the fingerprint chromatogram (Figure 2). Peak 4 (Routin) which is one of the most important active constituents in $C$. chinensis was chosen to calculate the relative retention time (RRT) and relative peak area (RPA). RPA and RRT of characteristic peaks in 9 samples are shown in Table 3 and Table 4 respectively. State Food and Drug Administration (SFDA) suggests that all herbal chromatograms should be evaluated in terms of similarity by calculation of the correlation coefficient and/or angle cosine value of original data [13]-[15]. The closer the cosine values are to 1 , the more similar the two chromatograms are. The similarity values of all the nine samples were more than 0.88 . Samples with the similarity less than 0.8 were regarded as nonqualified. Therefore, if 0.80 is set as an appropriate threshold, it is easy to identify acceptable based on the chromatographic fingerprint. The fingerprint patterns of the different samples are different, and by comparing the each fingerprint pattern with the median of all chromatograms, we can obtain the similarity value of each fingerprint pattern, which can help us to evaluate the quality of different samples. The similarities of chromatograms of nine samples comparing with the reference fingerprint, which was developed with the median of all chromatograms, were shown in Table 5 . As it was shown in Table 3 the contents of each individual marker determined between different samples, were significantly different with \%RSD (relative standard deviation) values beyond $40 \%$, indicating variations in their quality. A possible explanation of the result is that samples were collected from quite different hosts. It is noteworthy that quality consistency may not only be monitored by chromatographic fingerprint. For example, relatively higher similarity values (0.96, 0.98 and 0.99$)$ were obtained for samples S2, S4, S9 respectively, indicating the good quality consistency between samples were collected from different hosts. However, in the quantitative study, the contents of four major compounds (Routin, Hyperoside, Isorhamnetin and Kaempferol) were significantly different among these three samples. The RSD values for contents of the four markers fell in the range of $41.62 \%-77.85 \%$, which indicate that quality consistency of $C$. chinensis was different from host to host. Thus, more attention should be paid to quality consistency of C. chinensis from different hosts to ensure its clinical efficacy and safety. Results from this study agree with a previous study that found chromatographic fingerprinting combined with quantitative techniques for determining

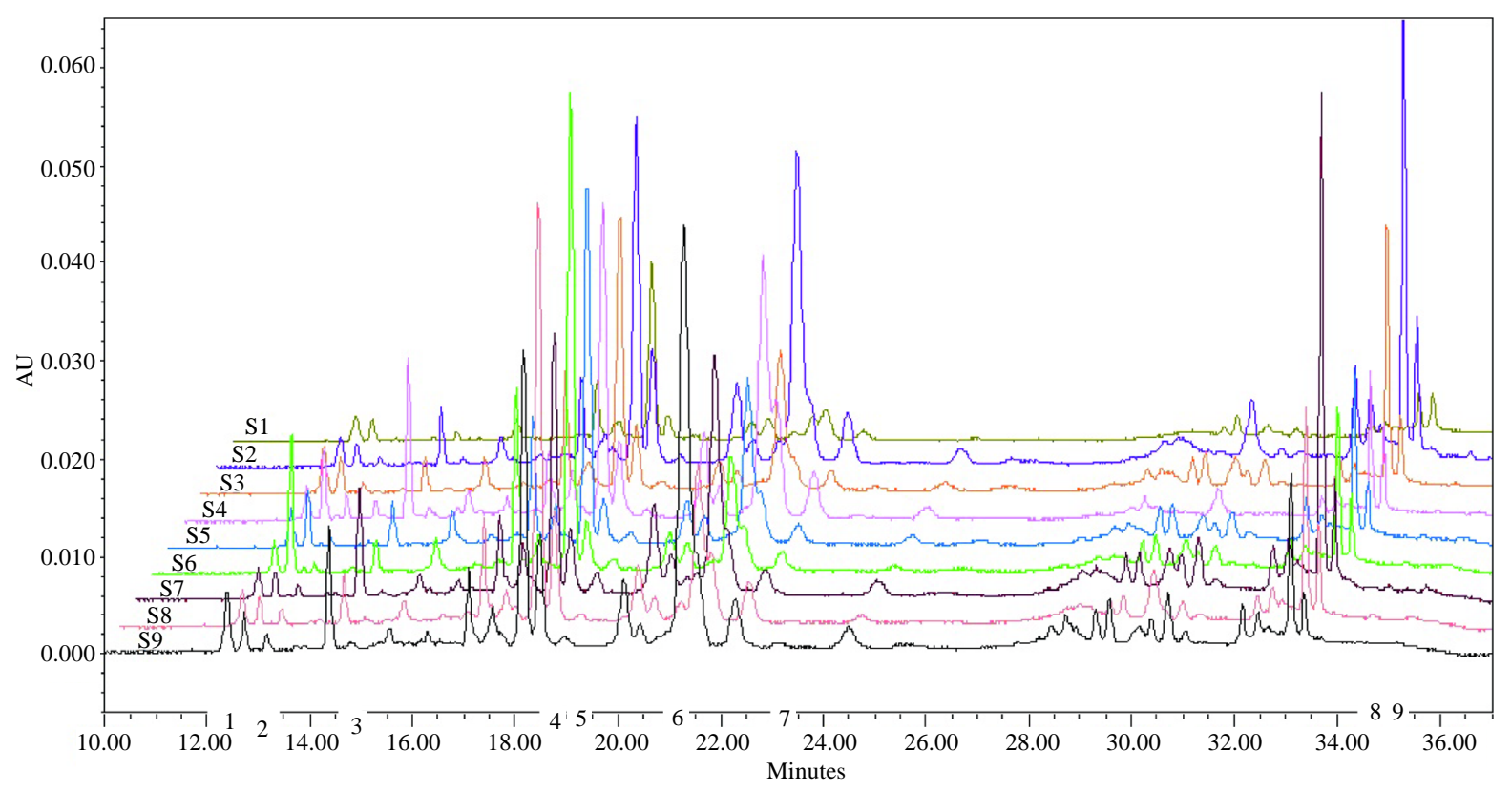

Figure 2. Characteristic peaks of $C$. chinensis on different hosts. 
Table 3. RPA in HPLC fingerprints of $C$. chinensis samples.

\begin{tabular}{ccccccccccc}
\hline Host & $\begin{array}{c}\text { Tanacetum } \\
\text { balsamita }\end{array}$ & $\begin{array}{c}\text { Foeniculum } \\
\text { vulgare }\end{array}$ & $\begin{array}{c}\text { Carthamus } \\
\text { oxycantha }\end{array}$ & $\begin{array}{c}\text { Artemisia } \\
\text { annua }\end{array}$ & $\begin{array}{c}\text { Datura } \\
\text { innoxia }\end{array}$ & $\begin{array}{c}\text { Vinca } \\
\text { minor }\end{array}$ & $\begin{array}{c}\text { Datura } \\
\text { stramonium }\end{array}$ & $\begin{array}{c}\text { Kochia } \\
\text { scoparia }\end{array}$ & $\begin{array}{c}\text { Alhagi } \\
\text { maurorum }\end{array}$ & RSD\% \\
\hline $\mathbf{1}$ & 0.213 & 0.240 & 0.088 & 0.172 & 0.109 & 0.102 & 0.065 & 0.125 & 0.094 & 44.86 \\
$\mathbf{2}$ & 0.112 & 0.095 & 0.058 & 0.101 & 0.107 & 0.169 & 0.212 & 0.077 & 0.052 & 46.98 \\
$\mathbf{3}$ & 0.293 & 0.036 & 0.119 & 0.088 & 0.116 & 0.314 & 0.051 & 0.295 & 0.087 & 72.00 \\
$\mathbf{4}$ (routin) & 1 & 1 & 1 & 1 & 1 & 1 & 1 & 1 & 1 & 0 \\
$\mathbf{5}$ & 0.419 & 0.126 & 0.362 & 0.251 & 0.142 & 0.267 & 0.121 & 0.275 & 0.289 & 41.62 \\
$\mathbf{6}$ & 0.350 & 0.123 & 0.327 & 0.130 & 0.194 & 0.343 & 0.108 & 0.492 & 0.192 & 52.68 \\
$\mathbf{7}$ & 0.263 & 0.075 & 0.275 & 0.108 & 0.083 & 0.232 & 0.064 & 0.128 & 0.165 & 53.28 \\
$\mathbf{8}$ & 0.576 & 0.158 & 0.838 & 0.564 & 0.323 & 0.267 & 0.222 & 1.280 & 0.322 & 71.33 \\
$\mathbf{9}$ & 0.658 & 0.190 & 0.251 & 0.143 & 0.133 & 0.130 & 0.094 & 0.279 & 0.131 & 77.85 \\
\hline
\end{tabular}

Table 4. RRT in HPLC fingerprints of $C$. chinensis samples.

\begin{tabular}{|c|c|c|c|c|c|c|c|c|c|c|}
\hline $\begin{array}{l}\text { Host } \\
\text { Peaks }\end{array}$ & $\begin{array}{c}\text { Tanacetum } \\
\text { balsamita }\end{array}$ & $\begin{array}{c}\text { Foeniculum } \\
\text { vulgare }\end{array}$ & $\begin{array}{l}\text { Carthamus } \\
\text { oxycantha }\end{array}$ & $\begin{array}{c}\text { Artemisia } \\
\text { annua }\end{array}$ & $\begin{array}{l}\text { Datura } \\
\text { innoxia }\end{array}$ & $\begin{array}{l}\text { Vinca } \\
\text { minor }\end{array}$ & $\begin{array}{c}\text { Datura } \\
\text { stramonium }\end{array}$ & $\begin{array}{l}\text { Kochia } \\
\text { scoparia }\end{array}$ & $\begin{array}{c}\text { Alhagi } \\
\text { maurorum }\end{array}$ & RSD \% \\
\hline 1 & 0.685 & 0.681 & 0.682 & 0.682 & 0.682 & 0.682 & 0.681 & 0.682 & 0.682 & 0.172 \\
\hline 2 & 0.702 & 0.700 & 0.699 & 0.700 & 0.699 & 0.699 & 0.699 & 0.699 & 0.700 & 0.108 \\
\hline 3 & 0.792 & 0.792 & 0.791 & 0.791 & 0.788 & 0.791 & 0.790 & 0.790 & 0.791 & 0.143 \\
\hline 4 (routin) & 1 & 1 & 1 & 1 & 1 & 1 & 1 & 1 & 1 & 0 \\
\hline 5 & 1.017 & 1.018 & 1.017 & 1.018 & 1.017 & 1.017 & 1.017 & 1.017 & 1.017 & 0.022 \\
\hline 6 & 1.107 & 1.107 & 1.107 & 1.107 & 1.106 & 1.107 & 1.106 & 1.107 & 1.107 & 0.039 \\
\hline 7 & 1.225 & 1.226 & 1.226 & 1.226 & 1.226 & 1.225 & 1.226 & 1.226 & 1.226 & 0.024 \\
\hline 8 & 1.820 & 1.823 & 1.821 & 1.822 & 1.821 & 1.821 & 1.822 & 1.821 & 1.822 & 0.045 \\
\hline 9 & 1.835 & 1.837 & 1.835 & 1.836 & 1.835 & 1.835 & 1.835 & 1.836 & 1.836 & 0.035 \\
\hline
\end{tabular}

Table 5. The similarities of chromatograms of $C$. chinensis samples.

\begin{tabular}{ccc}
\hline Host & Similarity index $^{*}$ & Similarity index $^{* *}$ \\
\hline Tanacetum balsamita & 0.9216 & 0.9085 \\
Foeniculum vulgare & 0.9579 & 0.9622 \\
Carthamus oxycantha & 0.9504 & 0.9341 \\
Artemisia annua & 0.9859 & 0.9748 \\
Datura innoxia & 0.9939 & 0.9873 \\
Vinca minor & 0.9694 & 0.9674 \\
Datura stramonium & 0.9662 & 0.9669 \\
Kochia scoparia & 0.8801 & 0.8357 \\
Alhagi maurorum & 0.9927 & - \\
\hline
\end{tabular}

*by using median, ${ }^{* *}$ by using Alhagi maurorum.

marker compounds a better tool for quality consistency evaluation of herbal preparations compared to chromatographic fingerprinting alone [16] [17].

\section{Conclusion}

Flavonoids are the main content of $C$. chinensis, which indicates that we can suggest flavonoids contents of $C$. chinensis as its markers compounds for quality control and set a minimum qualification for $C$. chinensis with 
their major flavonoids like routin, isorhamnetin, hyperoside and kaempferol. Through comparing the HPLC chromatograms (Figure 2), it was found that the content of flavonoids in C. chinensis samples from different hosts was different apparently from host to host. Fingerprint analysis was developed to assess the quality and comparative content of nine major components in C. chinensis samples collected from different hosts. The fingerprint analysis, performed on results from the HPLC analysis and using similarity index. The similarity of chromatographic fingerprint of nine samples was over 0.88 and their characteristic and specificity were apparent, which showed that the chromatogram profiles of samples were similar. However, the contents of routin, isorhamnetin, hyperoside and kaempferol of nine samples were different, which indicated that there were differences in quality among the samples from different hosts. So, it is suggested that the HPLC fingerprint method combined with quantitative analysis, is an efficient and comprehensive tool for quality consistency evaluation of $C$. chinensis collected from different hosts.

\section{References}

[1] Hajimehdipoor, H., Mokhtari, K.B., Amin, Gh., Adib, N., Rastegar, H. and Shekarchi, M. (2012) Development of a Validated HPLC Method for the Simultaneous Determination of Flavonoids in Cuscuta chinensis Lam. By Ultra-Violet Detection. DARU Journal of Pharmaceutical Sciences, 20, 57-62. http://dx.doi.org/10.1186/2008-2231-20-57

[2] Wang, Y., Li, Q., Wang, Q., Li, Y., Ling, J., Liu, L., Chen, X. and Bi, K. (2011) Simultaneous Determination of Seven Bioactive Components in Oolong Tea Camellia sinensis Quality Control by Chemical Composition and HPLC Fingerprints. Journal of Agricultural and Food Chemistry, 60, 256-260. http://dx.doi.org/10.1021/jf204312w

[3] Welsh, W.J., Lin, W.K., Tersigni, S.H., Collantes, E., Duta, R. and Carey, M.S. (1996) Pharmaceutical Fingerprinting: Evaluation of Neural Networks and Chemometric Techniques for Distinguishing among Same-Product Manufacturers. Analytical Chemistry, 68, 3473-3482. http://dx.doi.org/10.1021/ac951164e

[4] Collantes, E.R., Duta, R., Welsh, W.J., Zielinski, W.L. and Brower, J. (1997) Preprocessing of Hplc Trace Impurity Patterns by Wavelet Packets for Pharmaceutical Fingerprinting Using Artificial Neural Networks. Analytical Chemistry, 69, 1392-1397. http://dx.doi.org/10.1021/ac9608836

[5] Aksenova, T.I., Tetko, I.V., Ivakhnenko, A.G., Villa, A.E.P., Welsh, W.J. and Zielinski, W.L. (1999) Pharmaceutical Fingerprinting in Phase Space. 1. Construction of Phase Fingerprints. Analytical Chemistry, 71, 2423-2430. http://dx.doi.org/10.1021/ac981345r

[6] Hansen, L.B.A. (2001) A Stable Gas Chromatography-Mass Spectrometry Analysis System to Characterize Ma Huang Products Found in Health Foods and Supplements. Journal of Pharmaceutical Sciences, 90, 943-948. http://dx.doi.org/10.1002/jps.1045

[7] Cheng, Y.Y. and Chen, M.J. (2003) An Approach to Comparative Analysis of Chromatographic Fingerprints for Assuring the Quality of Botanical Drugs. Journal of Chemical Information and Computer Sciences, 43, 1068-1076. http://dx.doi.org/10.1021/ci034034c

[8] Cheng, Y.Y., Chen, M.J. and Welsh, W.J. (2003) Fractal Fingerprinting of Chromatographic Profiles Based on Wavelet Analysis and Its Application to Characterize the Quality Grade of Medicinal Herbs. Journal of Chemical Information and Computer Sciences, 43, 1959-1965. http://dx.doi.org/10.1021/ci034090d

[9] Li, W., Tang, Y., Chen, Y. and Duan, A.J. (2012) Advances in the Chemical Analysis and Biological Activities of Chuanxiong. Molecules, 17, 10614-10651. http://dx.doi.org/10.3390/molecules170910614

[10] Wang, L., Wang, X. and Kong, L. (2012) Automatic Authentication and Distinction of Epimedium koreanum and Epimedium wushanense with HPLC Fingerprint Analysis Assisted by Pattern Recognition Techniques. Biochemical Systematics and Ecology, 40, 138-145. http://dx.doi.org/10.1016/j.bse.2011.10.014

[11] Cao, Y., Wang, L., Yu, X. and Ye, J. (2006) Development of the Chromatographic Fingerprint of Herbal Preparations Shuang-Huang-Lian oral Liquid. Journal of Pharmaceutical and Biomedical Analysis, 41, 845-856. http://dx.doi.org/10.1016/j.jpba.2006.01.060

[12] Aghili Alavi Khorasani Shirazi, M.H. (2008) Makhzan-ol-Adviyeh [Source of plants]. Institute of Historical Studies, Islamic and Complementary Medicine, Medical University of Iran Press, Tehran, 142-144, 748-749.

[13] Feng, S.H., Hu, F.D., Zhao, J.X., Xu, J.W. and Chen, L.R. (2004) Studies on Chromatography Fingerprint of Hongi by High-Performance Liquid Chromatography. Chinese Chemical Letters, 15, 1335-1338.

[14] Wei, H., Sun, H., Tai, Z., Gao, S., Xu, W. and Chen, W. (2010) A Simple and Sensitive HPLC Method for the Simultaneous Determination of Eight Bioactive Components and Fingerprint Analysis of Schisandra sphenanthera. Analytica Chimica Acta, 662, 97-104. http://dx.doi.org/10.1016/j.aca.2009.12.039

[15] Wang, L.X., Xiao, H.B., Liang, X.M. and Bi, K.S. (2002) Vectorial Angle Method for Evaluating the Similarity between Two Chromatographic Fingerprints of Chinese Herb. Acta Pharmacologica Sinica, 37, 713-717. 
[16] Gong, F., Liang, Y.Z., Xie, P.S. and Chau, F.T. (2003) Information Theory Applied to Chromatographic Fingerprint of Herbal Medicine for Quality Control. Journal of Chromatography, 1002, 25-40. http://dx.doi.org/10.1016/S0021-9673(03)00648-4

[17] Lin, Y., Wu, T., Zhu, J., Wan, L., Yu, Q., Li, X., Cheng, Z. and Guo, C. (2010) Combinative Method Using HPLC Fingerprint and Quantitative Analyses for Quality Consistency Evaluation of an Herbal Medical Preparation Produced by Different Manufacturers. Journal of Pharmaceutical and Biomedical Analysis, 52, 597-602.

http://dx.doi.org/10.1016/j.jpba.2010.01.018

\section{List of Abbreviations}

- HPLC: High Performance Liquid Chromatography

- TIM: Traditional Iranian Medicine

- UV: Ultra Violet

- LSD: Last Significant Difference

- RRT: Relative Retention time

- RPA: Relative Peak Area

- SFDA: State Food and Drug Administration

- RSD: Relative Standard Deviation 